\title{
Transapical transcatheter device closure of relapse left ventricular diverticulum: a novel minimally invasive technique for reoperation
}

\author{
Weizhi Zhang, Lei Gao, Yifeng Yang and Tianli Zhao*
}

\begin{abstract}
We describe a novel minimally invasive technique, transapical transcatheter device closure of relapse left ventricular diverticulum (LVD) under transesophageal echocardiography (TEE) guidance. The patient previously underwent LVD primary repair and mitral valvular replacement. The anatomical characteristics of the relapse LVD and its adjacent structures are detailedly delineated by echocardiography. The relapse LVD is then managed by transapical transcatheter device closure under TEE guidance. This novel minimally invasive technique is not only limited in relapse LVD, but also could be extensively applied in other cardiac reoperation, such as perivalvular leak closure after valvular replacement.
\end{abstract}

Keywords: Cardiac reoperation, Minimally invasive technique, Echocardiography

\section{Dear Sir,}

A 12-year-old Chinese boy presents to us with exercise-induced dyspnea for 3 weeks. He underwent an open-heart surgery one year before. Diagnosis of isolated congenital left ventricular diverticulum (LVD) with mitral valve infective endocarditis was made intraoperatively, and the diverticulum was successfully repaired by direct suturing the orifice, and mitral valve was replaced with a $23 \mathrm{~mm}$ inverted supra-annular mechanical valve. Transthoracic echocardiography (TTE) was performed at discharge, one month and six months follow-ups, and all of which confirmed obliteration of the diverticulum with good function of mechanical valve and left ventricle (LV). On this admission, his heart rate is $110 \mathrm{bpm}$, the cardiac dullness is extended to the left and downward, and there is no heart murmur. Chest $\mathrm{x}$-ray film shows cardiomegaly (Fig. 1a). TTE shows markedly impaired LV function $(E F=38 \%$, FS $=19 \%)$, and a saccular structure $(38 \times 39 \mathrm{~mm})$ localized between the left atrium and the aortic root, communicating with the LV through a

\footnotetext{
* Correspondence: zhaotianli69@126.com

Department of Cardiovascular Surgery, The Second Xiangya Hospital of Central South University, 139 Middle Renmin Road, Changsha, Hunan 410011, China
}

before last surgery, suggestive of the relapse of the LVD.

To rescue the LV function resulted from the relapse LVD, we develop a novel minimally invasive technique, transapical transcatheter LVD device closure. Transesophageal echocardiography (TEE) is applied to perform a comprehensive study after general anesthesia and intubation, looking at all aspects of the LVD anatomy (location, size, neck and its adjacent structure) (Fig. 2a). The LVD neck is sized with the maximum diameter, which is $13 \mathrm{~mm}$. And a $16 \mathrm{~mm}$ atrial septal defect (ASD) occluder (Shanghai Shape Memory Alloy Co. Ltd., Shanghai, China) is chosen for LVD neck closure. The LV apex is identified by palpation and TTE. The pleural space overlying the apex is entered via a $3 \mathrm{~cm}$ anterolateral thoracotomy. The pericardium over the apex is identified and dissected. The thin portion of the apex is identified by finger palpation and confirmed by ultaneous TEE, and then a purse-string suture with et is placed. After puncture of the left ventricular ex, the guidewire is passed through the LVD neck into livery sheath is advanced into the diverticulum, just across the LVD neck. The guidewire is removed and the 

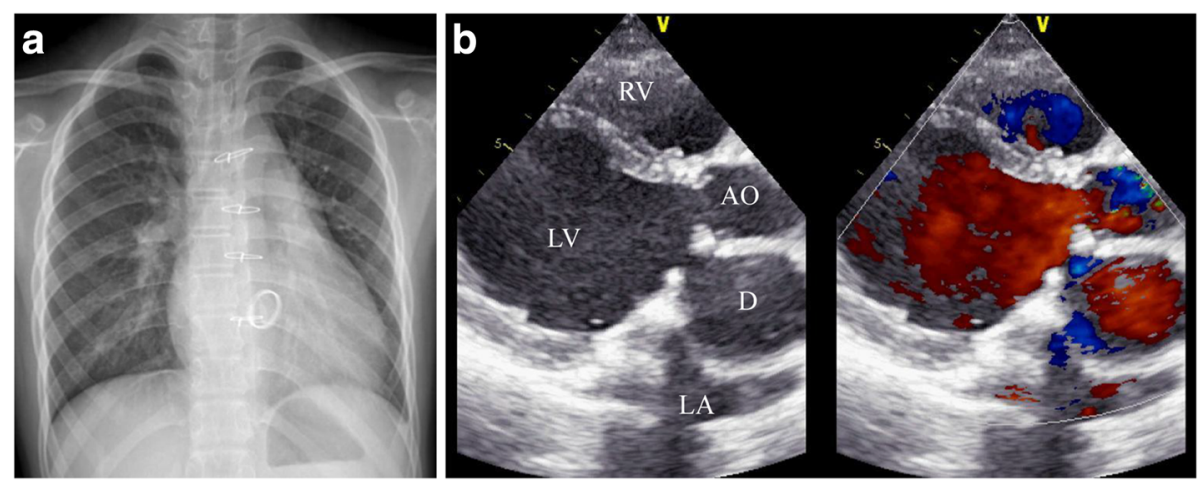

Fig. 1 Multimodality imaging of the relapse left ventricular diverticulum (D). a. Chest x-ray film shows cardiomegaly. b. Transthoracic echocardiography shows a saccular structure (D) localized between the left atrium $(L A)$ and the aortic root $(A O)$, communicating with the left ventricle (LV) through a $13 \mathrm{~mm}$ wide neck

delivery sheath is filled with blood to ensure de-airing (Fig. 2b). The loading sheath is then connected, and the ASD occluder is advanced. The device is released stepby-step under TEE guidance, with left disk deployed in the diverticulum (Fig. 2c), while the right disk in the LV (Fig. 2d). After confirmation of an adequate occlusion of the LVD neck, together with the documentation of undisturbed adjacent aortic and mitral valve function, the loading cable is released and the loading system is retrieved. Hemostasis is secured with the previously placed pledgeted suture. The chest is closed in a routine fashion. After an uneventful recovery the patient is discharged home on the 5th postoperative day, when the TTE confirms an adequate occlusion of the LVD, with improved LV function ( $E F=52 \%, F S=27 \%)$. No hydropericardium or hydrothorax was seen by TTE. Eight months of patient follow-ups do not show any discomfort, and last TTE indicates $\mathrm{EF}=67 \%, \mathrm{FS}=38 \%$.

The mechanism of the in situ relapse of the LVD in our case is unknown, though the fracture of the suture should be the most supposed reason [1]. We prefer a new minimally invasive technique, transapical transcatheter LVD device closure, rather than conventional reopen heart surgery in this case for several reasons. First, the deep-seated localization of the LVD, makes the dissection and surgical resection of the diverticulum technically difficult during a reoperation. Also, the exposure and suturing of the orifice can be problematic if repair the LVD inside LV, because of the mechanical mitral valve implanted in the first operation. Second, the minimally invasive technique permits the avoidance of a resternotomy and re-cardiotomy. Instead, only a direct
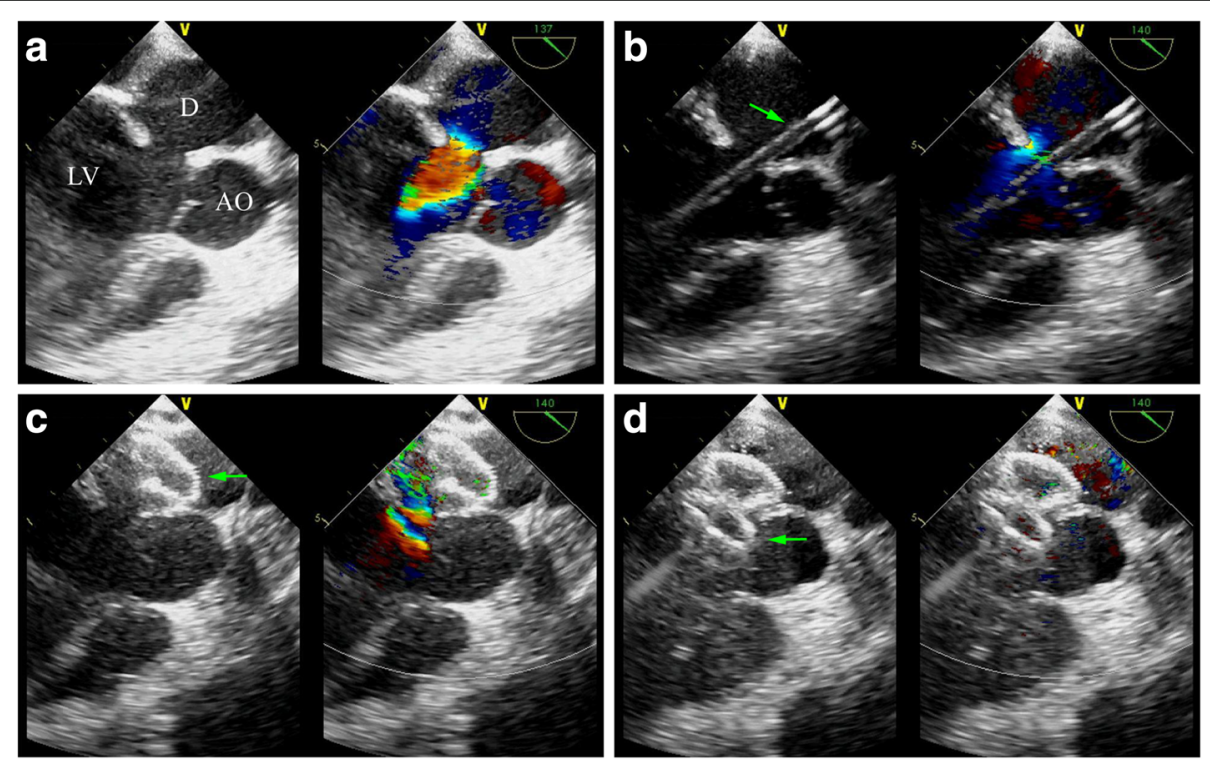

Fig. 2 Surgical approach of transapical transcatheter device closure of relapse left ventricular diverticulum under transesophageal echocardiography (TEE) guidance. LV, left ventricle; AO, aorta; D, left ventricular diverticulum 
puncture in the left ventricular apex is performed. Third, this technique avoids cardiopulmonary bypass. In the meanwhile, we always keep in mind the potential complications, such as rupture of diverticulum, valve injury, device drop-off, embolism, and arrhythmia. The successful application of the transapical transcatheter device closure in the relapse LVD case demonstrates the usefulness and feasibility of this new technique. Moreover, this technique is not only limited in relapse LVD, but also could be extensively applied in other cardiac reoperation, such as perivalvular leak closure after valvular replacement.

\section{Abbreviations}

ASD: Atrial septal defect; LV: Left ventricle; LVD: Left ventricular diverticulum; TEE: Transesophageal echocardiography; TTE: Transthoracic echocardiography

\section{Acknowledgements}

Not applicable.

\section{Funding}

Not applicable.

\section{Availability of data and materials}

Not applicable.

\section{Authors' contributions}

WZ and TZ conducted the literature research, the writing and revision of the draft, the production of the figure and the final approval of the letter. LG and $Y Y$ contributed to the writing and critical revision of the manuscript. TZ is the author responsible for this letter. All authors read and approved the final manuscript.

\section{Competing interests}

The authors declare that they have no competing interests.

\section{Consent for publication}

Consent to publish was obtained from the patient's parents.

\section{Ethics approval and consent to participate}

All procedures were in accordance with institutional guidelines and were approved by the institutional review committee. Study approval was obtained from the Committee on Clinical Applications at The Second

Xiangya Hospital of Central South University.

Received: 3 August 2016 Accepted: 9 November 2016

Published online: 16 November 2016

\section{Reference}

1. Ohlow MA, von Korn H, Lauer B. Characteristics and outcome of congenital left ventricular aneurysm and diverticulum: analysis of 809 cases published since 1816. Int J Cardiol. 2015:185:34-45.

Submit your next manuscript to BioMed Central and we will help you at every step:

- We accept pre-submission inquiries

- Our selector tool helps you to find the most relevant journal

- We provide round the clock customer support

- Convenient online submission

- Thorough peer review

- Inclusion in PubMed and all major indexing services

- Maximum visibility for your research

Submit your manuscript at www.biomedcentral.com/submit 